\title{
O sacrifício do boi para Ogum: explorando três fotografias sobre Candomblé no acervo do jornal $A$ Tarde
}

The sacrifice of the ox for Ogum: exploring three photographs on candomblé in the archive of the periodical $A$ Tarde

\author{
Cleidiana Ramos \\ Mestre em Estudos Étnicos e Africanos pela Universidade Federal da Bahia \\ E-mail: cleidiana@uol.com.br
}

RESUMO

O presente artigo analisa fotografias do rito de sacrifício de um boi para ser oferecido ao orixá Ogum, ocorrido no Terreiro de Ogum, que ficava localizado em Lauro de Freitas, município pertencente à Região Metropolitana de Salvador (RMS), na Bahia. Estes registros, inseridos no acervo do jornal $A$ Tarde, são um ponto de partida para a análise das relações entre o fotojornalismo e as religiões afro-brasileiras.

Palavras-chave: Candomblé; Sacrifício; Fotojornalismo

\section{Abstract}

This paper analyzes photos of ritual sacrifice of an ox to be offered to the orixa (orisha) Ogun, occurred in the Terreiro (Shrine) of Ogun, who was located in Lauro de Freitas, a municipality belonging to the Metropolitan Area of Salvador (RMS), Bahia. These records, which integrates the archive of newspaper A Tarde, are a starting point for analyzing the relationship between photojournalism and african-brazilian religions.

Keywords: Candomblé; Sacrifice; Photojournalism 
1 - Uma pesquisa divulgada pelo Instituto Verificador de Circulação (IVC) apontou A Tarde como o periódico de maior crescimento na Região Nordeste. Sua circulação é o dobro da apresentada pelo segundo colocado no ranking dos jornais baianos, 0 Correio. (A Tarde, 29/8/2009, caderno especial sobre a reforma gráfica, p.4).

2 - A dissertação foi orientada pelo Prof. Dr. Claudio Luiz Pereira.

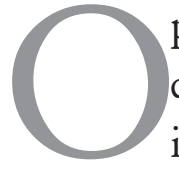

presente artigo apresenta considerações sobre três fotografias do sacrifício de um boi no candomblé baiano. As fotos estão inseridas no acervo do jornal $A$ Tarde, [1] localizado em Salvador, Bahia, e integram um conjunto de 1.432 imagens catalogadas para a dissertação de mestrado de minha autoria intitulada "O discurso da luz imagens das religiões afro-brasileiras no Arquivo do Jornal $A$ Tarde", apresentada à Faculdade de Filosofia e Ciências Humanas da Universidade Federal da Bahia (FFCH-Ufba) em dezembro de 2009. [2]

O Arquivo $A$ Tarde é um centro de documentação ainda pouco explorado mesmo pelos profissionais da redação do jornal. Estima-se que lá estão armazenadas cerca de 100 mil pastas, englobando as que contêm textos e fotografias. O jornal foi fundado em 1912, mas a organização do arquivo só aconteceu em 1975, ano em que foi completamente abandonado o uso dos clichês - as placas de chumbo que eram utilizadas para a reprodução das imagens nas páginas do jornal. Infelizmente, os poucos clichês que ainda restavam não tiveram as suas imagens convertidas para a "fotografia de papel" por conta do alto custo para a transição.

As fotografias relacionadas às religiões afro-brasileiras estão distribuídas em 51 pastas. Para a dissertação, foram escolhidas 50 fotografias, inclusive as que serão apresentadas neste artigo e que mostram o ritual de sacrifício de um boi para Ogum no Terreiro de Ogum, que ficava localizado em Lauro de Freitas, município da Região Metropolitana de Salvador (RMS).

A seleção de um grupo de fotografias ocorreu com o objetivo de ser possível uma análise mais detalhada. Destas, $80 \%$ foram realizadas nas décadas de 70 e 80, com uma ligeira predominância (46\%) do primeiro período citado.

Os critérios utilizados para selecionar as fotografias foram a relevância histórica das imagens; sua capacidade de registrar aspectos definidores das diferentes modalidades das religiões afro-brasileiras (candomblé, umbanda, jarê etc); rituais no espaço interno e externo dos terreiros; as funções hierárquicas; registros de Mãe Menininha do Gantois, por ser a personagem com maior número de pastas temáticas no Arquivo; oráculos; polêmicas envolvendo as comunidades religiosas; relações com 
o poder e ritos fúnebres. Cada um destes critérios nomeou uma categoria onde estão reunidos grupos de fotos.

Embora a pesquisa englobe fotografias do período que vai dos anos 1950 aos 2000, ela ficou restrita às imagens que estão em papel, mesmo as que foram feitas com tecnologia digital. $\mathrm{O}$ acervo mostrou possuir documentos significativos. Isto porque até as minhas atividades de pesquisa, as fotografias repousavam numa espécie de liminaridade. Este conceito, presente no livro Imagens do Sagrado, de autoria de Fernando de Tacca, aplica-se bem a esta coleção.

Segundo o autor, as fotografias em formato analógico experimentam uma existência latente quando ainda estão em negativo até se tornarem visíveis via o processo conhecido como "revelação", que acontece com a utilização de recursos químicos. Quando são guardadas após este período, elas voltam para a condição de liminaridade (TACCA, 2009: 159-162).

Este conceito me pareceu também adequado por ser bem presente em estudos antropológicos que tratam de religiões. As fotografias do acervo de $A$ Tarde estão num limite em que lhes é possível, mesmo com a sua existência no papel, ficar "invisíveis" quando estão recolhidas nas pastas onde estão classificadas e, de repente, ao ser solicitadas por um repórter ou editor, recuperar a sua razão de ser, que é a visibilidade. Elas estão, portanto, numa posição, que lembra a ambiguidade com relação a estados diferentes de que fala Turner (1974).

Como são imagens construídas no universo do fotojornalismo, as perguntas que surgem ao contemplá-las são as mesmas utilizadas para identificar o lead, que é o recurso tradicionalmente usado para começar a elaboração de um texto jornalístico, a partir da fórmula $3 \mathrm{Q}+\mathrm{C}+\mathrm{O}+\mathrm{P}(\mathrm{o}$ quê? quem? quando? como? onde? por quê?).

As perguntas do lead podem ser mais facilmente respondidas numa análise de imagens por meio do modelo proposto por Bóris Kossoy. Ele sugere a decodificação da imagem fotográfica a partir da identificação dos seus elementos constitutivos (fotógrafo, assunto e tecnologia) e as suas coordenadas de situação - espaço e tempo (KOSSOY, 2007: 46) -, modelo que foi adotado por mim para a análise das fotografias. 
Segundo o autor, a escolha por estes elementos é por conta da sua importância para que a fotografia aconteça:

O produto final, a fotografia, é, portanto, resultante da ação do homem, o fotógrafo, que em determinado espaço e tempo optou por um assunto em especial e que, para seu devido registro, empregou os recursos oferecidos pela fotografia (KOSSOY, 2001, p. 37).

Estes elementos deixam de ser puramente descritivos no momento em que, de acordo com Kossoy, vão aparecendo outros detalhes da história que eles retratam. Este princípio é confirmado nesta análise à medida que as reportagens em que estas fotos aparecem são localizadas. Em alguns casos, as imagens revelam detalhes que não aparecem nos textos, a partir de outras fontes disponíveis, como entrevistas com membros das comunidades dos terreiros. Nas fichas descritivas da análise das fotografias optei por manter os dados de sua catalogação no jornal, o que pode facilitar a consulta de interessados em pesquisar outros aspectos das imagens desta coleção.

Vale ressaltar que a minha condição de repórter contratada por $A$ Tarde facilitou o acesso ao objeto de pesquisa, o que justificou o meu esforço para manter a rotina profissional no jornal paralelamente ao desenvolvimento do mestrado. A conciliação do trabalho com a pesquisa foi uma tarefa árdua, mas o meu afastamento da empresa poderia criar obstáculos, inclusive do ponto de vista prático, tornando mais difícil o acesso às informações. No ambiente de trabalho, seguidamente, consegui informações importantes durante a conversa com um colega que tem mais tempo de atuação na empresa.

A minha especialização profissional na cobertura dos temas afrobrasileiros, exercitada tanto no jornal como num blog do portal online da mesma empresa, o "Mundo Afro", também ajudou muito na busca de dados para este trabalho. A proximidade que mantenho com religiosos de candomblé e umbanda facilitou tanto a identificação dos personagens das fotografias como de muitas situações que elas retratam. 


\section{Passos Reveladores}

Trazer estas imagens de volta à sua condição de "existência", ao ficarem visíveis, foi o primeiro passo da minha pesquisa e o que possibilitou reunir informações que enriquecem a sua condição de documento ao, por exemplo, identificar os seus personagens e contextualizar historicamente os acontecimentos que determinaram a origem destes registros.

Foi também o início da trajetória para tentar entender esta relação delicada e contraditória entre o candomblé e a fotografia. Embora os barracões dos terreiros exibam retratos de pessoas importantes para a história dos templos, os registros fotográficos nestes espaços ainda são tidos como algo proibido, inclusive com a exibição de placas ostentando esta restrição. Mas a regra é mais vigente nos templos mais tradicionais, existindo uma tolerância maior nos fundados mais recentemente.

(...) Nos rituais que presenciei no terreiro de Mãe Tunga, foram as próprias pessoas da casa que tiraram as fotos, ou pessoas que eles mesmos convidaram para fotografar, com o intuito de que as imagens registradas sejam entregues à casa. Por outro lado, a lei do segredo é ainda aplicável: os rituais públicos podem ser fotografados, mas ninguém, nem os mais velhos, tem a permissão para fotografar os rituais privados (CASTILLO, 2008: 77).

Segundo a autora, a permissividade passa pela questão do uso. É possível maior controle em relação aos registros feitos por pessoas da própria comunidade, o que é mais difícil em relação aos realizados por quem é de fora. Esta avaliação torna ainda mais valiosa a coleção estudada, pois não só os registros foram gerados por agentes externos aos terreiros, como para uso comercial em um meio de comunicação de massa.

O levantamento das reportagens que exigiram estas fotos mostra que as religiões afro-brasileiras, sobretudo o candomblé, ocupam um lugar de importância no imaginário baiano para mobilizar a cobertura de um órgão da chamada grande imprensa.

Das 50 fotografias escolhidas, $72 \%$ foram utilizadas em reporta- 
gens. Mesmo dentre os $28 \%$ em que não ficou comprovado este uso, há casos da publicação de imagens realizadas no mesmo dia e cenário.

São dados importantes, pois, embora a Bahia tenha tradição na produção de conhecimento sobre temas afro-brasileiros, sediando a pesquisa para estudos pioneiros e que já se tornaram clássicos, como os de Nina Rodrigues, Manuel Querino, Arthur Ramos, Édison Carneiro, Ruth Landes, Roger Bastide, Vivaldo da Costa Lima, Pierre Verger, dentre outros, as imagens produzidas sobre o candomblé baiano que aparecem nessas pesquisas funcionam como uma espécie de prova do discurso científico.

Já a abordagem dos fotojornalistas está voltada para a produção em massa e, portanto, seguindo regras que dizem ser notícia aquilo que é inusitado e capaz de despertar a curiosidade do seu público. Este caráter do jornalismo e, especificamente, do fotojornalismo foi o centro de dois conhecidos embates entre a imprensa e o candomblé baiano. As polêmicas surgiram em torno das fotografias sobre o rito iniciático mais conhecido como "feitura de santo", publicadas em 1951 na revista francesa Paris Match e na brasileira O Cruzeiro.

A reportagem da Paris Match foi publicada em 12 de maio de 1951 com o título "As possuídas da Bahia". O texto anunciava o lançamento do livro O Cavalo dos Deuses, do cineasta Henri-Georges Clouzot, que veio ao Brasil com a pretensão de fazer um filme sobre o país e durante uma passagem pela Bahia escolheu o candomblé como tema de uma série fotográfica.

O texto e as fotografias da Paris Match, que mostram detalhes de um processo de iniciação comandado por um sacerdote chamado no texto de Nestor, um nome fictício, receberam severas críticas de intelectuais, como Alberto Cavalcanti e Roger Bastide. Como resposta $\mathrm{O} C r u-$ zeiro publicou em 15 de setembro de 1951 uma reportagem semelhante assinada por Arlindo Silva e com fotografias feitas por José Medeiros, intitulada "As noivas dos deuses sanguinários".

As fotos do passo-a-passo do rito de iniciação, como a epilação (raspagem dos cabelos) e as iaôs - nome que se dá a quem passa pelo ritual - sendo banhadas com o sangue de animais, provocaram até a 
convocação, via jornais, de uma reunião da Federação Baiana do Culto Afro-Brasileiro (Febacab) para discutir as duas reportagens. No imaginário coletivo circulava a versão de que a mãe-de-santo que permitiu o registro, Mãe Riso de Plataforma, morreu anos depois de forma misteriosa e violenta, e as iaôs, além de não ter a iniciação reconhecida, foram punidas com a loucura e a morte.

O livro de Tacca, citado anteriormente, traz a desmistificação dessa história por meio de um trabalho cuidadoso de reconstituição com base em entrevistas de personagens que conviveram com Mãe Riso. O levantamento do autor apresenta detalhes da vida da sacerdotisa, que morreu no Rio de Janeiro, em 1993, por "causas naturais" e não de forma violenta, como dá conta a versão que ainda circula entre o povo-de-santo. As três iaôs que aparecem na reportagem também não tiveram a iniciação cancelada, como foi divulgado na época.

A pesquisa para a análise destas e das outras fotografias que compõem a dissertação feita por mim seguiu uma linha semelhante à do trabalho feito por Tacca, embora só tenha tido contato com ele já no processo de finalização. Esta aproximação de metodologia está, talvez, na mesma procedência do objeto estudado: o fotojornalismo. Foram as fotografias que forneceram as primeiras pistas para reconstruir os episódios que as tornaram possíveis.

O texto, quando foi localizado, completou as informações que elas deixavam latentes. Em alguns casos, as imagens possibilitaram o recolhimento de dados que não estão escritos. Desta forma, um acervo como o de $A$ Tarde pode contribuir para as pesquisas no campo das Ciências Sociais. BURKE (2004), por exemplo, define a fotografia como um poderoso meio de representação. Mas vale lembrar que este status nem sempre é reconhecido, como afirma Bóris Kossoy:

A imagem, em especial a fotográfica, sempre se viu tradicionalmente relegada à condição de 'ilustração' dos textos e 'apêndice' da história. No entanto, a documentação iconográfica é uma das fontes mais preciosas para o conhecimento do passado (...) (KOSSOY, 2007: 31). 
3 - Uma análise sobre o discurso da imprensa baiana, inclusive A Tarde, nos últimos 50 anos, está sendo feita pelo doutorando em História Social Jaime Sodré. Já tive acesso a algumas sessões de apresentação dos dados do seu trabalho, mas a tese ainda não foi defendida.
No caso do jornalismo impresso, a fotografia é um componente indispensável, não apenas como complementação do texto, mas como outra perspectiva do mesmo fato relatado, a ponto de ter uma denominação específica: fotojornalismo. Não há o chamado "jornal de papel” sem as fotografias.

Assim, os dados trazidos por este tipo de análise, a meu ver, podem abrir novas possibilidades para a pesquisa sobre o relacionamento entre as religiões afro-brasileiras e a imprensa que vão além da análise dos textos, área já analisada tanto nas pesquisas clássicas como em outras mais recentes: LÜHNING (1995-1996), SANTOS (2005), PARÉS (2006), CASTILLO (2008) e REIS (2008). [3]

Considero o acesso que tive a este acervo de imagens um privilégio, pois, além de ser a primeira pesquisa com esta abordagem em relação à coleção de $A$ Tarde, ainda são muito poucos os registros fotográficos de religiões como o candomblé fora do campo da etnografia, como pode ser classificada a produção de Pierre Verger. Em relação ao fotojornalismo, mesmo sem este recorte temático, ainda existem poucos estudos sistematizados.

\section{FotOJORNALISMO}

A análise feita aqui é baseada na produção de documentos que envolvem o universo afrorreligioso baiano a partir do trabalho de profissionais ligados a um veículo de comunicação comercial. Diferentemente dos autores de estudos antropológicos ou etnográficos, eles não tinham como objetivo principal analisar o que viam, mas apenas registrar aspectos do ambiente dos terreiros, embora, como toda construção fotográfica, ela tenha implicações de ordem subjetiva (KOSSOY, 2001, 2007).

Vale lembrar que a fotografia em jornal é utilizada como uma forma de conferir autenticidade ao que é narrado no texto. Mas, como é uma linguagem diferente, nem sempre ela se limita a corroborar o que está escrito, permitindo interpretações que vão além do que narra a reportagem.

Este trabalho não realiza uma análise da estrutura das religiões afro-brasileiras ou uma revisão crítica dos estudos clássicos sobre elas. $\mathrm{O}$ principal objetivo é exibir como estas manifestações religiosas foram 
representadas, através da fotografia, em um órgão de comunicação de massa.

As fotografias do acervo mostram a representação, em um importante veículo de comunicação de massa, do dia-a-dia dos terreiros, nome que se dá aos espaços destinados à prática do candomblé e da umbanda.

\section{As IMAGENS DO SACRIFÍCIO DO BOI}

A série de fotografias analisadas a seguir mostra o ritual de abate de um boi para ser oferecido ao orixá Ogum. Elas foram publicadas na reportagem intitulada "A grande festa de Ogum", veiculada em $A$ Tarde no dia 31 de julho de 1980 , na página 14 do Caderno 2. O texto e as imagens fazem uma descrição pormenorizada do ritual.

A primeira fotografia [FIG. 1] mostra o animal já abatido e, ao fundo, pessoas em transe. Já na segunda imagem, [FIG. 2] o destaque é para a mulher deitada no chão, numa posição em que não dá para ver detalhes do seu rosto, pois ele está encoberto por uma máscara formada pelo seu cabelo, o que confere ainda maior dramaticidade à fotografia.

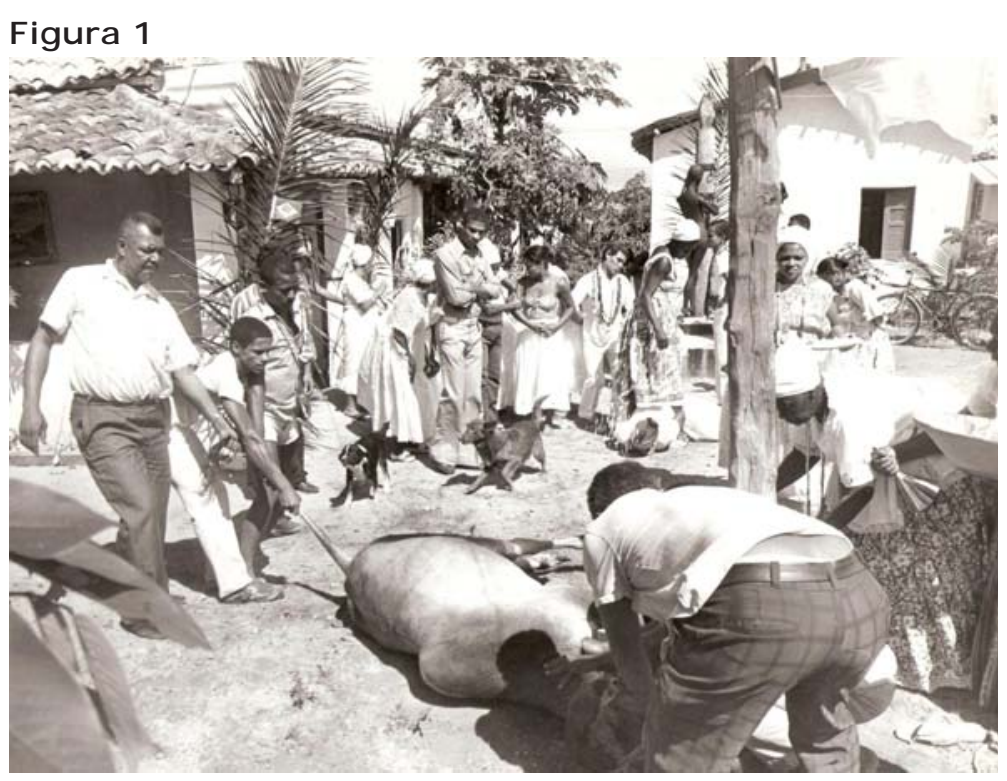

Elementos constitutivos da fotografia - Fotógrafo: Reynivaldo Brito; Assunto: sacrifício de boi para Ogum; Personagens identificados: apenas o hoje pai-de-santo Valdemir Melo. É o sacerdote que está em estado de transe, entre duas mulheres, com as mãos para trás; Catalogação em $\boldsymbol{A}$ Tarde: Pasta Candomblé $n$ ㅇ 6901-B; Tecnologia: analógica, preto-e-branco; Coordenadas de situação - Tempo: 31/7/1980; Espaço: Terreiro de Ogum, Lauro de Freitas, Bahia

\section{Figura 2}

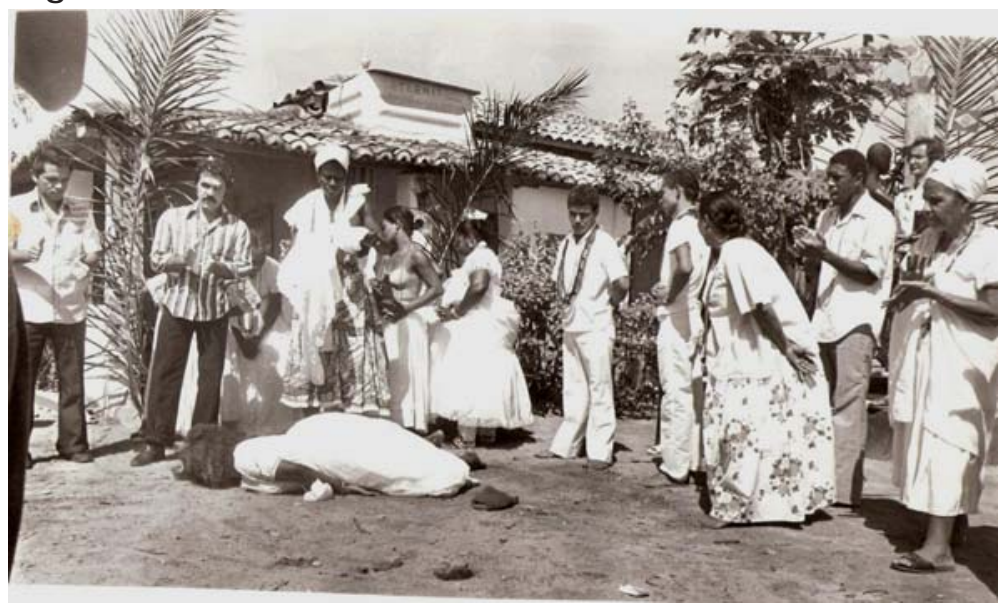

Elementos constitutivos da fotografia - Fotógrafo: Reynivaldo Brito; Assunto: sacrifício de boi para Ogum; Personagens identificados: Pai Valdemir Melo, à frente da mulher com saia estampada no lado direito da imagem. Mulher em transe, deitada no chão, é consagrada a Oxumarê, mas os informantes não se lembraram do nome dela; Catalogação em $\boldsymbol{A}$ Tarde: Pasta Candomblé no 6901-B; Tecnologia: analógica, preto-e-branco; Coordenadas de situação - Tempo: 31/7/1980; Espaço: Terreiro de Ogum, Lauro de Freitas, Bahia 


\section{Figura 3}

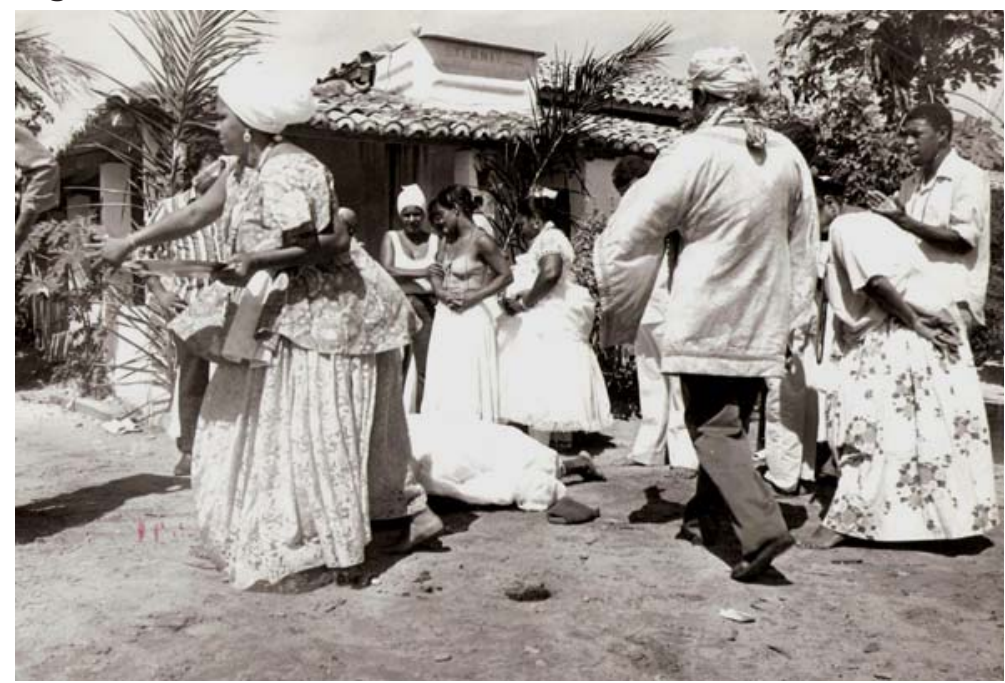

Elementos constitutivos da fotografia - Fotógrafo: Reynivaldo Brito; Assunto: sacrifício de boi para Ogum; Personagens identificados: Pai Zé de Ogum, de turbante, aparece de costas. Catalogação em A Tarde: Pasta Candomblé no 6901-B; Tecnologia: analógica, preto-e-branco; Coordenadas de situação - Tempo: 31/7/1980; Espaço: Terreiro de Ogum, Lauro de Freitas, Bahia
A última das fotos [FIG. 3] mostra o comandante do terreiro, Pai Zé de Ogum, em direção ao local onde a mulher está em transe. À sua frente, uma mulher paramentada com roupas de candomblé segue à frente espalhando o conteúdo do prato que segura.

O terreiro era comandado por José Santos Araújo, mais conhecido como Zé de Ogum, já falecido. Para produzir as imagens, o repórter de texto Reynivaldo Brito, que ocasionalmente também fotografava, em entrevista à autora deste trabalho, contou que passou três dias chegando bem cedo ao terreiro e só saía quando o ritual terminava.

Eu fiz várias matérias para $A$ Tarde e para a Manchete. Como a Manchete gostava muito dessas coisas de Bahia, houve uma época que saíram mais de dez páginas com Zé de Ogum. Ele ficou assim muito vaidoso. Aí eu tinha um acesso fácil, e tudo que era festa ele queria que eu fosse.

Já as fotografias que saíram na revista Manchete, cuja edição não consegui localizar, foram realizadas por uma repórter fotográfica enviada para acompanhar Reynivaldo. Nessa época, ele era o correspondente da Manchete na Bahia. A revista foi um dos mais importantes periódicos brasileiros.

O depoimento de Reynivaldo revela como ficava mais fácil a produção de uma reportagem sobre detalhes mais reservados da estrutura do candomblé para os repórteres que tinham maior intimidade com o dia-adia dos terreiros. Assistir a um sacrifício ou "matança", como este rito também é chamado no jargão do candomblé, ainda hoje é uma prática 
geralmente reservada e que conta com a participação apenas de quem é membro da comunidade religiosa.

A permissão para fazer as fotografias que seriam publicadas em um jornal mostra que o repórter tinha conquistado a confiança do comandante do terreiro, mas também revela a troca envolvendo esta interação: o repórter ganhava a oportunidade de contar uma história que tinha um dos princípios básicos para ser considerada notícia, que é a capacidade de aguçar o interesse do leitor, e o terreiro ganhava proeminência, pois $A$ Tarde era o mais conhecido periódico baiano e a Manchete tinha circulação nacional.

Uma amostra da importância deste registro pode ser medida pela reação dos religiosos de candomblé entrevistados para a pesquisa. A maioria ficou pouco à vontade diante das fotos dos ritos de sacrifício.

A justificativa mais repetida para o desconforto foi a preocupação de que fotografias deste tipo possam ser utilizadas para fins de difamação do candomblé, principalmente em programas de TV das denominações neopentecostais, como a Igreja Universal do Reino de Deus (Iurd), que é constantemente acusada de praticar intolerância religiosa. [4] Mas a maioria dos que externaram seu desconforto pediu anonimato em relação a esta questão, para não desrespeitar o que consideram uma regra básica do candomblé: cada Casa tem as próprias normas de conduta.

Se as fotografias ainda causam desconforto 30 anos após a sua produção, na época não foi diferente, de acordo com Reynivaldo:

Quando a matéria saiu, algumas pessoas ligadas ao candomblé acharam um absurdo eu ter fotografado a cerimônia, né? Porque eu fotografei da hora em que amarraram o boi até quando botaram lá a cabeça com mel. Fiquei até acabar a festa.

Não é comum que repórteres de texto também realizem as fotos, mas Reynivaldo repetiria este procedimento em outras coberturas relacionadas a candomblé. A explicação para esse acúmulo de funções é a sua paixão por fotografia. Quando era possível, ele não dispensava a oportunidade de exercitar profissionalmente um hábito que começou como
4 - O fundador da lurd, Edir Macedo, escreveu um livro chamado Orixás, Caboclos e Guias, Deuses ou Demônios?, onde ataca princípios da umbanda, espiritismo, candomblé e catolicismo. $O$ Ministério Público Federal entrou com uma ação que resultou na retirada do livro de circulação, mas em seguida uma decisão dos tribunais superiores liberou a venda. 
hobby ao adquirir uma câmera Nikon, que é uma marca de referência para os fotógrafos.

Ao tempo em que fazia as imagens, ele conseguiu também captar as informações para fazer em seu texto uma descrição detalhada da cerimônia:

(...) Os toques eram cada vez mais fortes, e minutos depois acontecia a "primeira manifestação de um orixá. Uma senhora negra de cabelos quase embranquecidos começou a rodopiar e caiu ao solo, sendo imediatamente atendida pela mãe-pequena do terreiro, que é a segunda pessoa do candomblé. (...) $\mathrm{O}$ círculo foi se fechando e os toques aumentando. Um ligeiro golpe, e o boi caiu tremendo, enquanto o sangue era apanhado em uma grande tigela de barro para ser oferecido ao orixá. Ao término da sangria foram cortados a cabeça, as mãos, as pernas e os testículos para oferecer a Ogum. (...) O sangue que saiu de suas veias e artérias foi levado para o Ibá, que é uma espécie de santuário onde fica o carrego do santo com os potes, bacias e louças. Ali, o sangue, que eles chamam de menga, foi colocado em cima dos otás, que são pedras sagradas, com mel e vinho, que é o néctar do orixá (BRITO, 1980: 14).

Esta narrativa confirma ainda mais a liberdade desfrutada pelo repórter durante a cerimônia. Por sua descrição, parece que ele conseguiu, inclusive, acesso aos quartos sagrados. Outras informações presentes no texto de Reynivaldo revelam mais detalhes da rotina da Casa de Santo. Ele conta que os participantes da cerimônia são obrigados a permanecer 14 dias no terreiro, sem poder sair, e que o rito tem como principal objetivo assegurar 14 anos de paz para a comunidade onde ele acontece.

(...) Explicaram os membros do terreiro que a paz está garantida até 14 anos, mas salientaram que, para que isto se concretizasse, eles tiveram antes de sacrificar sete galos caboclos (vermelhos) para Exu, que erradamente é sincretizado por pessoas alheias ao culto como o diabo. Dizem eles que no terreiro 
existem dois exus, o Xoroquê e o Tiriri, sendo este último confundido com escravo, quando na realidade é um orixá (Idem: 14).

A festa, de acordo com o texto de Reynivaldo, foi marcada pela fartura: distribuição de feijão, carne assada e ensopado. A descrição dos pormenores do ritual continua na reportagem:

Numa grande panela, foi preparado o ixê de Exu, que é constituído dos miúdos dos sete galos caboclos (cabeças, pés, fígados, bofes e vísceras) cozidos com azeite de dendê e em seguida colocados aos pés de Exu. O restante dos galos também foi aproveitado para o xinxim feito com camarão e azeite e distribuído entre os presentes à cerimônia no primeiro e no segundo dia. Exu estava "assentado” e Ogum já dominava tudo.

\section{Feijoada de Ogum}

Finalmente os integrantes do terreiro alcançam o verdadeiro auge da festa com a grande feijoada de Ogum. Quartorze homens devidamente escolhidos pelo pai-de-santo e ajudados por algumas filhas-de-santo começam a preparar o barracão principal para a cerimônia. No centro do barracão, foram colocados três esteiras e três alas (lençóis) brancos e em volta jarros com flores e castiçais com velas. As filhas-de-santo se acercaram, também os ogãs, alabê, ekedes, kotas, mãepequena e outros membros do candomblé e algumas traziam tabuleiros com pipocas que eles chamam de flores para o velho Omolu. O doburú foi trazido porque o velho Omolu é amigo inseparável de Ogum, principalmente de Ogum de Ronda [...] (Ibidem: 14).

Os detalhes da reportagem ajudam a contextualizar as fotografias, mas elas, à primeira vista, já indicam que se trata de um ritual religioso: a postura das pessoas, com olhos fechados, as mãos para trás ou na 


\section{Figura 4}

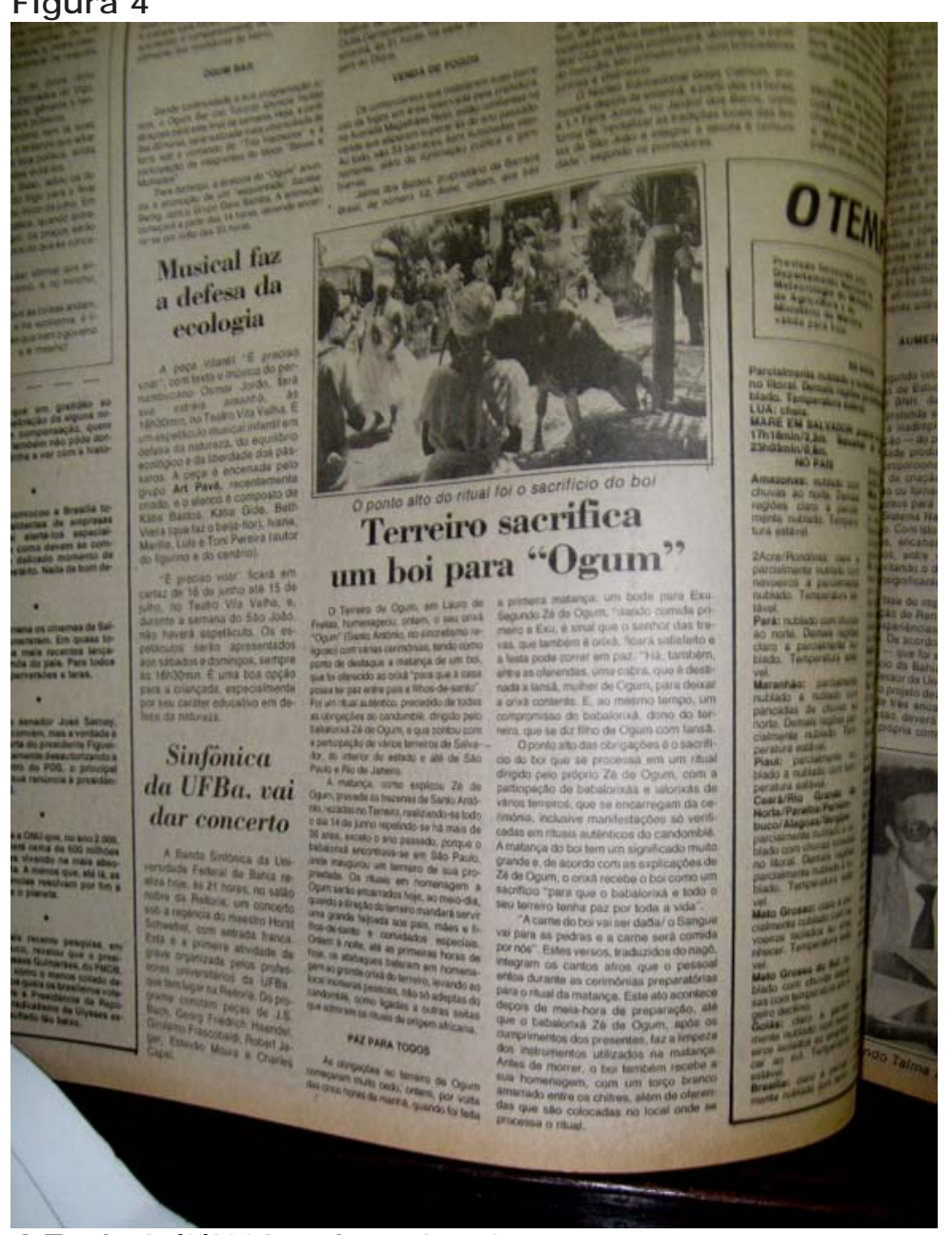

A Tarde, 15/6/1984, caderno 1, p. 2 cintura dão indicações de que estão em um estado de transe. A segunda foto é ainda mais explícita com a sacerdotisa deitada no chão.

Não há elementos para medir como esta matéria foi recepcionada pelo público do jornal. A polêmica, com base no depoimento de Reynivaldo, parece ter mesmo ficado restrita ao ambiente dos terreiros, mas tudo indica que não incomodou Zé de Ogum, pois na edição de 15 de junho de 1984, mais uma vez foi publicada uma reportagem sobre o ritual intitulada "Terreiro sacrifica um boi para Ogum”. [FIG. 4]

Desta vez o espaço foi menor e saiu apenas uma foto que parece ser da mesma sequência das feitas quatro anos antes. $\mathrm{O}$ espaço de publicação também mudou: saiu do Caderno 2 , que tradicionalmente nos jornais é voltado para assuntos culturais, e foi para o noticiário de cidade: primeiro caderno e página 2 .

A foto utilizada na matéria não está nas pastas da coleção de $A$ Tarde. Pode ter se perdido, o que todo o cuidado dos responsáveis pelo arquivo não pôde impedir diante da alta rotatividade do material de pesquisa que acontecia antes do processo da consulta digital atualmente em vigência. Mas dá para notar que o espaço é bem reduzido em relação à matéria anterior e que a imagem é bem menos descritiva do que as outras. Aparece apenas o boi em pé e mais nada que indique detalhes do rito. Seria uma maneira de amenizar os efeitos da publicação anterior?

A descrição do ritual só aparece no título "Terreiro sacrifica um boi 
para Ogum" e na legenda: "O ponto alto do ritual foi o sacrifício do boi". É bem diferente das usadas na reportagem anterior, que faziam descrições de etapas do ritual.

A legenda da primeira fotografia exibida na reportagem de 1980, onde aparece o boi abatido, diz: "O axogum com uma grande peixeira sangra o boi para oferecer o sangue a Ogum”, embora a cena não apareça. Já a segunda faz uma referência ao estado de transe: "Quando o alabê iniciou o toque, as filhas-de-santo ficaram manifestadas".

A mais curiosa, na minha opinião, é a legenda da terceira fotografia, onde Zé de Ogum aparece de costas: "Zé de Ogum comandou toda a solenidade com muita firmeza e seriedade". A meu ver, esta afirmação é uma espécie de prevenção às críticas que certamente viriam pela exibição do ritual. Melhor então destacar a postura "correta" do sacerdote.

Outro dado interessante é que, embora o terreiro seja definido pelo repórter como de tradição angola, todos os termos utilizados são do vocabulário do candomblé ketu: alabê, que é o sacerdote músico; orixá, quando as divindades cultuadas nesta nação são chamadas de inquice, dentre outras. A única referência à nação angola é a palavra "kota", uma variação de "makota", que é equivalente à palavra equede da tradição ketu, nome que se dá à sacerdotisa que tem funções de assessoria durante o ritual e que não entra em transe.

É compreensível imaginar o desconforto que a publicação da matéria causou no ambiente dos terreiros, afinal o que, para os leitores de $A$ Tarde, pode não ter passado de uma satisfação de curiosidade foi a divulgação de um dos aspectos mais solenes do candomblé.

Este rito é o veículo para o reforço da energia das divindades. Elas se alimentam do que emana das oferendas que recebem. Não é à toa que determinadas partes dos animais (vísceras, cabeça, dentre outras) reservadas para os deuses são chamadas de "axé". [5]

Estas e outras fotografias da coleção são surpreendentes por tratarse de registros realizados com o objetivo de ilustrar reportagens quando o discurso ainda muito presente entre o povo-de-santo, como é também chamada a comunidade de candomblé, é o de que não se permite a fotografia de seus ritos. $\mathrm{O}$ princípio seria ainda mais rígido em relação a um tema tão
5 - Manoel

Nascimento da

Costa, em Frutos da

Memória e da

Vivência - O Grande

Sacrifício do Boi na

Nação Nagô e

Outras Tradições

dos Xangôs do

Recife, faz uma

abordagem

detalhada sobre a

importância e

significado do

sacrifício de

animais. $A$

referência de Costa

é o Xangô,

presente,

principalmente, em

Pernambuco, mas

a sua descrição é

muito próxima da

forma como o

sacrifício é

entendido pelos

religiosos do

candomblé. Ele

também aborda no

texto o passo-a-

passo da matança

de um boi, mas

num rito dedicado a

Xangô e, portanto,

diferente dos

procedimentos que

foram detalhados

na reportagem. $O$

texto está in Moura.

Marcondes Carlos

Eugênio de. (org).

As Senhoras do

Pássaro da Noite.

São Paulo: Edusp,

1994. 
sensível como o sacrifício de animais, daí a minha escolha desta série de fotografias para este artigo.

Nas festas públicas dos terreiros, ainda hoje, é comum observar a atuação vigilante dos ogãs - nome que se dá aos ocupantes de um dos postos da hierarquia do candomblé - para impedir as fotografias. Percebi esta resistência também por conta da minha atividade profissional, pois, como repórter especializada na cobertura de temas ligados à identidade negra e religiosidade, especialmente nos últimos seis anos, não realizei nesse período nenhum tipo de reportagem ligada à reprodução de qualquer ritual.

As reportagens tanto em $A$ Tarde como em outros jornais da cidade limitam-se à abordagem histórica, descritiva da estrutura do candomblé e da umbanda ou das suas ações sociais. As imagens de rito que uma vez ou outra têm aparecido são, geralmente, de arquivos, o que me levou à conclusão de que este "fechamento" à imprensa é recente.

O desconforto que estas imagens de sacrifício ainda causam em sacerdotes e sacerdotisas do candomblé me levaram a perceber que a construção de uma relação de intimidade do repórter com o terreiro, como foi descrita pelo autor destas imagens, Reynivaldo Brito, era fundamental para a sua produção. Era também uma espécie de troca: o repórter tinha acesso a um tema capaz de despertar o interesse do leitor do jornal e o terreiro, por sua vez, ganhava proeminência ao aparecer num periódico importante.

Esta série de fotografias é apenas uma amostra das informações que o acervo oferece para a reconstrução de episódios da história das religiões afrobrasileiras na Bahia. Acredito que as imagens pertencentes ao Arquivo $A$ Tarde são documentos que chegam para enriquecer as pesquisas sobre estas manifestações religiosas

\section{REFERÊNCIAS BibLIOGRÁFICAS}

BURKE, Peter. Testemunha Ocular - História e Imagem. Bauru: Edusc. 2004.

CASTILO, Lisa Earl. Entre a Oralidade e a Escrita - A Etnografia nos Candomblés da Bahia. Salvador: Edufba, 2008.

BRITO, Reynivaldo. “A grande festa de Ogum”. In: A Tarde, edição de 31/7/1980, Caderno 2, p. 14 
COSTA, Manoel do Nascimento. "Frutos da memória e da vivência: o grande sacrifício do boi na nação nagô e outras tradições dos Xangôs do Recife”. In: MOURA, Carlos Eugênio Marcondes de. (org). As Senhoras do Pássaro da Noite. São Paulo: Edusp, 1994.

KOSSOY, Boris. Fotografia \& História. $2^{\circ}$ Edição Revisada. São Paulo: Ateliê Editorial. 2001.

. Os Tempos da Fotografia - O Efêmero e o Perpétuo. Cotia: Ateliê Editorial, 2007.

LÜHNING, Angela. "Acabe com este santo, Pedrito vem aí...mito e realidade da perseguição policial ao candomblé baiano entre 1920 e 1942, 1995-1996”. In: www.usp.br/revistausp/28/14-angela.pdf

PARÉS, Luis Nicolau. A Formação do Candomblé - História e Ritual da Nação Jeje na Bahia. Campinas: Unicamp. 2006

SANTOS, Jocélio Teles dos. O Poder da Cultura e a Cultura no Poder A Disputa Simbólica da Herança Cultural Negra no Brasil. Salvador: Edufba, 2005

REIS. João José. Domingos Sodré - Um Sacerdote Africano ? Escravidão, Liberdade e Candomblé na Bahia do Século XIX. São Paulo: Companhia das Letras, 2008

TACCA, Fernando Cury de. Imagens do Sagrado: Entre Paris Match e O Cruzeiro. Campinas: Unicamp/Imprensa Oficial do Estado de São Paulo, 2009.

TURNER, Victor W. O Processo Ritual: Estrutura e Antiestrutura. Petrópolis: Vozes, 1974. 